\title{
Current diagnosis and management of blunt traumatic rupture of the thoracic aorta
}

\author{
Estado atual do diagnóstico e tratamento das lesões \\ traumáticas da aorta torácica
}

Vishal Bansal, ${ }^{1}$ Jeanne Lee, ${ }^{1}$ Raul Coimbra ${ }^{2}$

\begin{abstract}
The diagnosis and management of aortic lacerations has been gradually improving. Historically, aortic lacerations were a common cause of exsanguination with extremely high mortality rate. However, in modern trauma systems with advanced resuscitation and rapid radiology imaging, the diagnosis of an aortic injury is improving with an emphasis on preventing the progression of intimal flaps and pseudoaneurysms to frank dissection or rupture. Both diagnostic modalities and the paradigm of immediate operative intervention have changed. The evolution of endovascular stenting may play a future role in definitive care.
\end{abstract}

Keywords: Thoracic trauma, thoracic aorta, thoracic aortic rupture, endovascular repair, endoprosthesis, stent graft, paraplegia.

\section{Introduction}

Traumatic rupture of the thoracic aorta is the most lethal injury following blunt chest trauma, accounting for 30 to $40 \%$ of all deaths in motor vehicle accidents. Complete full-thickness transection of the thoracic aorta is rapidly fatal in the field and is rarely the presenting etiology for exsanguinating hemorrhage during hospital trauma resuscitations. Other degrees of aortic injury, specifically partial thickness lacerations and dissections are often detected after initial trauma resuscitation and stabilization. Most often, patients arriving at the hospital alive will have a partial or

\section{Resumo}

O diagnóstico e tratamento das lesões traumáticas da aorta torácica vêm gradualmente melhorando. Historicamente, as lesões traumáticas da aorta torácica eram causa freqüente de exanguinação, apresentando altas taxas de mortalidade. Por outro lado, após o desenvolvimento de sistemas modernos de atendimento às vítimas de traumatismos, com protocolos avançados de reanimação volêmica e rápida avaliação radiológica, o diagnóstico de lesões da aorta torácica tem melhorado significativamente. A ênfase atual está centrada na prevenção da progressão das lesões intimais menores e pseudo-aneurismas até a dissecção franca ou ruptura aórtica. As modalidades diagnósticas sofreram alterações, bem como o paradigma de intervenção cirúrgica imediata. A evolução de próteses endovasculares poderá desempenhar um importante papel no tratamento definitivo.

Palavra-chave: Trauma torácico, aorta torácica, ruptura traumática da aorta torácica, tratamento endovascular, endoprótese, paraplegia.

complete circumferential tear of the aortic wall, surrounded by a hematoma contained by the periaortic dense connective tissue, thus forming a pseudoaneurysm. Most thoracic aortic injuries are detected because of clinical suspicion based on mechanism and the initial trauma chest radiographs leading to further definitive diagnostic measures. The initial management of these injuries varies based on the location and severity of the aortic injury and the patient's overall physiologic condition and prognosis. Treatment implements a combination of pharmacologic and surgical techniques; however, mortality of these patients remains high. The

1. MD. Trauma and Surgical Critical Care Fellow, University of California, San Diego School of Medicine, San Diego, CA, USA.

2. MD, PhD, FACS. Professor of Sugery. Chief, Division of Trauma, Surgical Critical Care, and Burns, University of California, San Diego School of Medicine, San Diego, CA, USA.

Manuscript received Nov 22, 2006, accepted for publication Feb 22, 2007. 
emergence of endovascular stenting (EVS) is increasingly playing a role in definitive repair, although long term efficacy has yet to be established.

\section{Incidence and etiology}

Blunt thoracic aortic injury from motor vehicle accidents (MVA) are the predominant cause in most Western nations. ${ }^{1}$ Civilian violence encapsulates most penetrating aortic trauma, however, given the increased use of percutaneous cardiac and vascular procedures, iatrogenic etiology is an increasingly recognized cause of injury. $^{2}$

Blunt thoracic aortic injury carries an extremely high mortality and remains the second leading cause of death, after head injury, in MVA with more than $80-90 \%$ dying at the scene. ${ }^{3}$ In the American Association for the Surgery of Trauma (AAST) multi-center institutional study, Fabian et al. reported MVA as the causative factor in greater than $80 \%$ of blunt thoracic aortic injuries. ${ }^{4}$ In one large retrospective, autopsy study almost $70 \%$ of traumatic thoracic aortic rupture were due to MVA, $17 \%$ from pedestrian versus auto, $8 \%$ from motorcycle accidents, and $4 \%$ from falls. ${ }^{5}$ The incidence of thoracic aortic transection is rare in the pediatric population; however, retrospective studies show that $47 \%$ of these injuries occur from falls of an average of 6 m high. ${ }^{6}$

The location of these injuries has given rise to several proposed mechanisms. The majority of these injuries involve the proximal descending thoracic aorta, within millimeters of the ligamentum arteriosum (aortic isthmus). The ascending aorta and mid-distal thoracic aorta represent a less likely location of injury. ${ }^{7}$ The descending thoracic aorta remains fixed at the ligamentum arteriosum, and therefore a high velocity impact causes differential deceleration and a sheering force effect leading to aortic wall tearing. Complete transection through all three layers may result in near instantaneous death if bleeding is not contained by the dense periaortic tissue (Figure 1). Partial thickness, noncircumferential tearing, usually sparing the adventitia and mediastinal pleura, gives raise to several possible lesions. In 1958, Parmley classified the lesions into six groups: 1) intimal hemorrhage; 2) intimal hemorrhage with laceration; 3) medial laceration; 4) complete transection; 5) pseudoaneurysmal formation; 6) periaortic hemorrhage. ${ }^{8}$

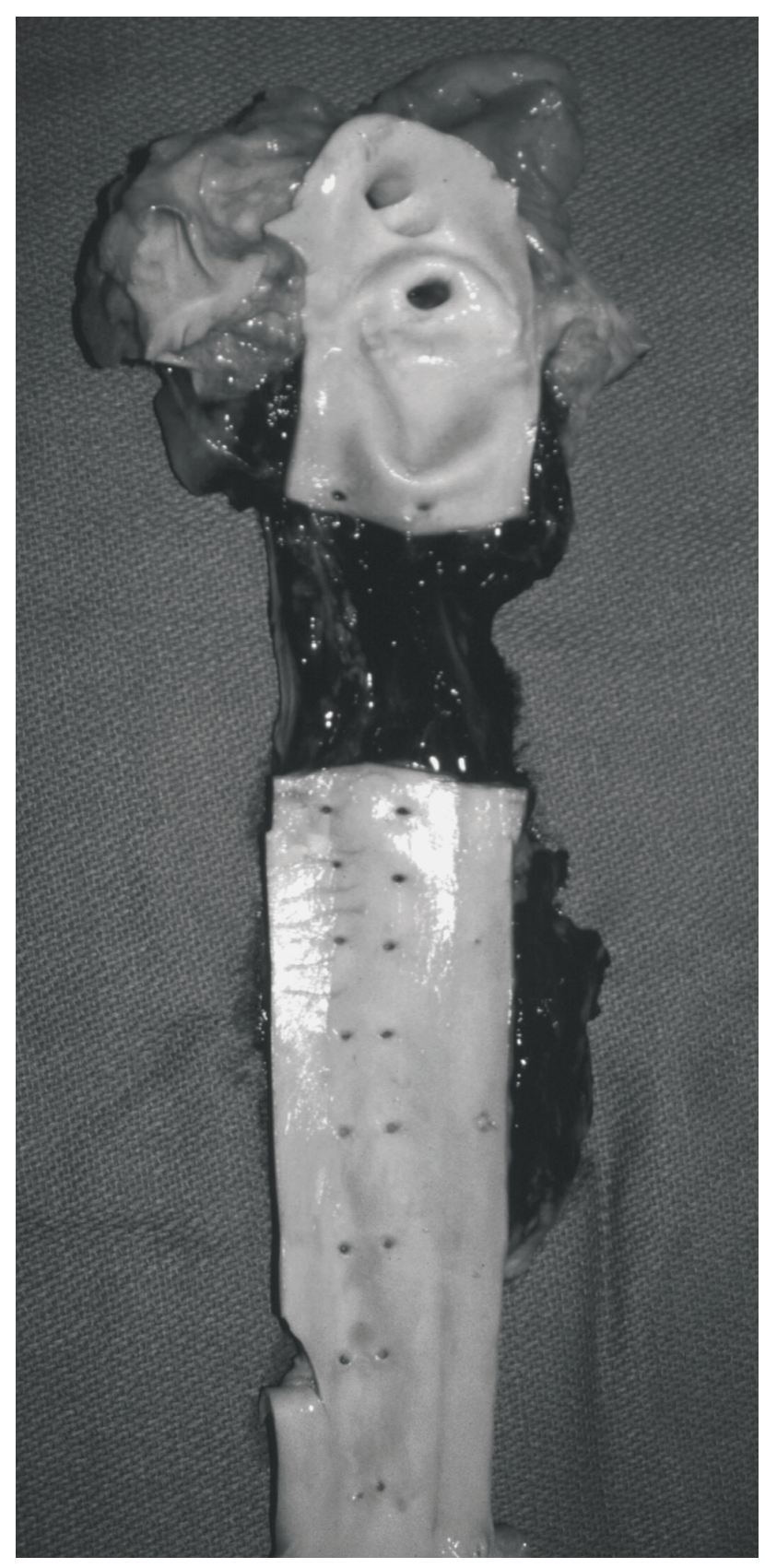

Figure 1 - Gross specimen from autopsy showing a complete aortic transection with periaortic tissue and clot surrounding the tear

Recently, an "osseous pinch" mechanism of aortic injury has been postulated. ${ }^{9}$ Cohen et al. reconstructed chest computed tomography (CT) scans of 22 known 
traumatic thoracic aortic ruptures finding the site of aortic injury corresponding to sandwiching of the thoracic aorta between the anterior spine and the anterior bony complex (sternum, first rib, or clavicle). Isolated case reports have reported similar findings. ${ }^{10}$ Regardless of the exact mechanism, patients sustaining massive chest trauma associated with rapid deceleration (i.e. MVA or falls) should carry suspicion of thoracic aortic injury until empiric diagnostic evaluation is complete.

\section{Diagnosis}

The most important factor in preventing a delay in diagnosis is the arousal of clinical suspicion based on mechanism of injury. ${ }^{11}$ Classically, thoracic aortic rupture secondary to blunt trauma has been associated with head-on MVA. ${ }^{8}$ However, lateral impact is an often overlooked mechanism of thoracic aortic injury in addition to head-on front impact accidents. In a review of 81 autopsy reports from deaths as a result of thoracic aortic rupture from MVA, lateral impact from side MVA were responsible for $49.5 \%$ of the injuries. ${ }^{12}$

Classic signs or symptoms of thoracic aortic injury may be absent upon presentation. The presence of other significant chest injuries and the appropriate mechanisms may raise the suspicion of a blunt thoracic aortic injury (Table 1). Physical examination may reveal differences in upper extremity pulses or suggest a pseudocoarctation syndrome, characterized by upper extremity hypertension and lower extremity hypotension. Neurologic deficits due to spinal cord ischemia without spinal fracture rarely occur. Clinical exam is notoriously nonspecific and described findings such as an intracapsular murmur or pseudocoarctation are unlikely to be appreciated during a trauma resuscitation. ${ }^{13}$ Sternal and rib fractures, chest wall ecchymosis, flail segments, hemo/ pneumothorax, solid organ injuries, and pelvic fractures should all indicate high energy impact and should heighten awareness of thoracic aortic injury.

Plain chest radiographs have been a standard in discerning the early detection of thoracic aortic trauma (Figure 2). Early studies have formulated an extensive list of chest radiographic findings indicating thoracic
Table 1 - Physical examination findings that may suggest an aortic injury
Hypotension
Upper extremity hypertension
External evidence of major chest trauma
Intracapsular murmur
Palpable fracture of thoracic spine/ sternum
Left flail chest

aortic injury, including blunting of the aortic knob, an apical cap, a widened mediastinum ( $>8 \mathrm{~cm}$ at the arch), and the presence of a basilar hemothorax, amongst others, with sensitivities ranging from $80-92 \%{ }^{14,15}$ (Table 2). Patel et al. combined positive chest radiograph findings with clinical suspicion and elevated the sensitivity of plain radiographs to $98 \%{ }^{16}$

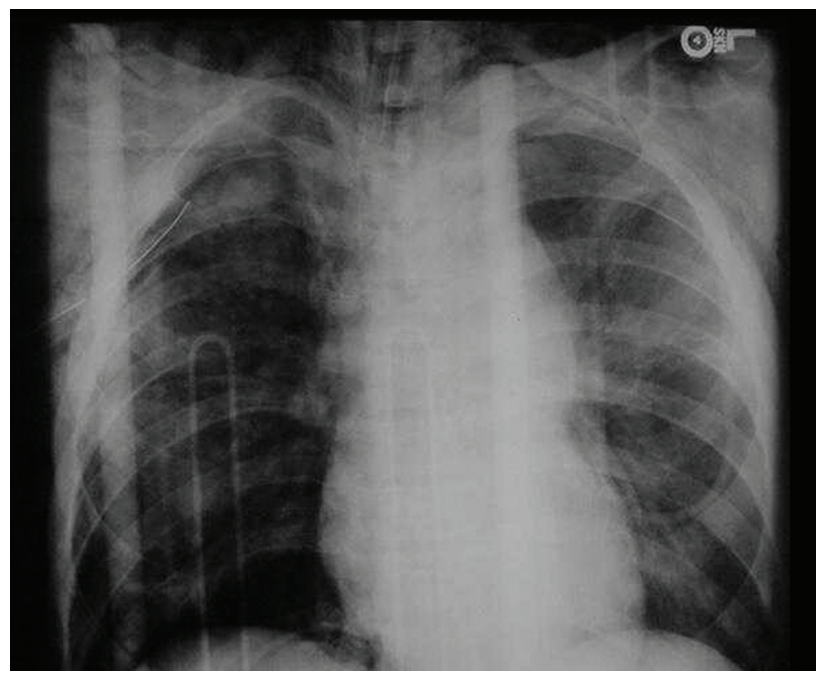

Figure 2 - A chest radiograph from a patient involved in a high speed head-on motor vehicle accident. The blunted aortic contour and mediastinal width greater than $8 \mathrm{~cm}$ in combination with the mechanism of injury should heighten suspicion for an aortic injury

The most common radiographic abnormality is widened mediastinum ( $>8 \mathrm{~cm}$ ), although only 20 to $43 \%$ of patients with a widened mediastinum have a thoracic aortic injury. However, the utility of chest radiographs in the diagnosis of blunt aortic injury was questioned in a recent study evaluating 188 consecutive blunt trauma patients who underwent chest radiogra- 
Table 2 - Common chest radiograph abnormalities found in aortic injuries

Mediastinum greater than $8 \mathrm{~cm}$

Abnormal aortic contour

Shift of endotracheal tube and/or trachea to the right

Depression of the left main stem bronchus

Depression of the right main stem bronchus

Deviation of the nasogastric tube to the right

Presence of apical pleural cap

First rib fracture

Acute left sided hemothorax

Retrocardiac density

phy and aortography. The study demonstrated that radiographic signs on plain chest films carry low specificity and no improvement in overall accuracy. ${ }^{17}$

Therefore, there are several important factors to bear in mind when reviewing the literature. Foremost is the fact that these findings are based on upright chest radiographs, thus decreasing projection and magnification artifact appreciated on supine studies. This is complicated by the difficulty in obtaining upright plain films during initial trauma resuscitations secondary to a patient's injury status. The finding of a widened mediastinum may be an indirect determinant of thoracic aortic injury being a result more from bleeding small vessels contained within the mediastinum hemorrhage than from aortic bleeding or an aortic pseudoaneurysm, therefore giving low positive predictive values. ${ }^{14}$ Furthermore, there are several reports documenting thoracic aortic rupture with normal initial chest radiographs. ${ }^{18}$ Therefore, at best, plain chest radiographs can serve as a marker for further diagnostic evaluation and should not be used as sole criteria for either excluding or confirming thoracic aortic injury.

\section{Computed tomography versus angiography versus echocardiography}

Given the low positive predictive value of plain chest radiographs, there has been enduring debate over the best radiographic technique to establish definitive diag- nosis. Establishing early diagnosis of thoracic aortic injuries is essential in order to begin therapeutic intervention.

Thoracic aortography is the gold standard for diagnosing blunt thoracic aortic injury with sensitivity and specificity nearing 100\% (Figure 3). However, even though aortography is safe, it is resource intensive, invasive, expensive, and most importantly, time consuming. For this reason, the diagnostic value of chest CT became of increasing interest throughout the 1990s. Previously, chest and abdominal CT have been used as a screening tool detecting periaortic hematomas or posterior mediastinal blood, both of which are highly specific for thoracic aortic rupture but had decreased sensitivity compared to aortography. ${ }^{19}$ However, the wider use of newer, helical CT angiograms (CTA) have increased sensitivity and specificity to as high as $97.8-100 \%$ and a $100 \%$ negative predictive value nearing the values established for aortography (Figures 4 and 5). ${ }^{20,21}$ Dyer et al. also noted significant cost savings of CTA when compared to traditional aortography for diagnosis. ${ }^{21}$

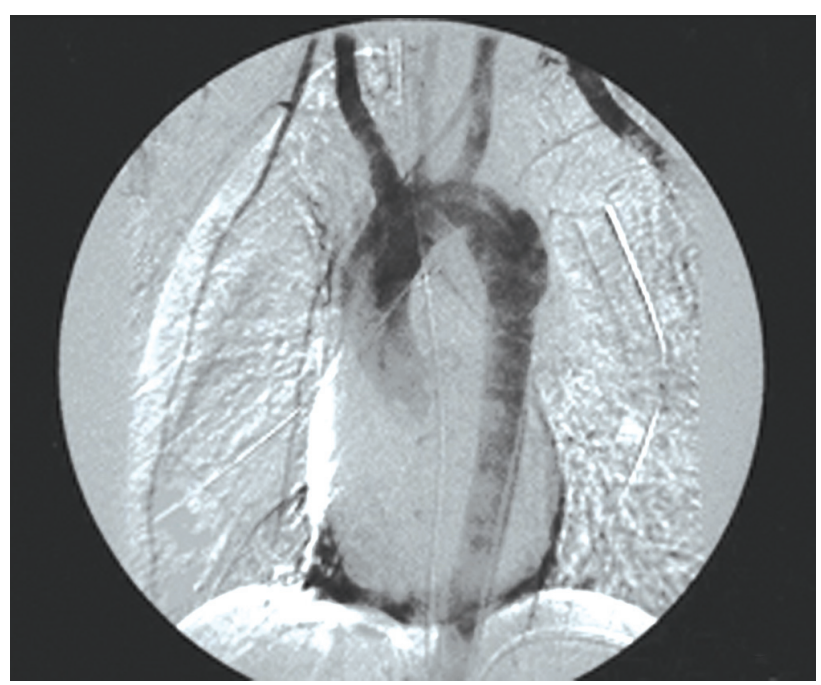

Figure 3 - Aortogram of a patient who fell from two stories high identifies a traumatic pseudoaneurysm in proximity of the aortic isthmus

Early criticism of CT scans centered around the possibility of high false negative readings since 3-9\% have been reported in previously published articles. ${ }^{22}$ However, scrutiny of these studies shows variable scan- 


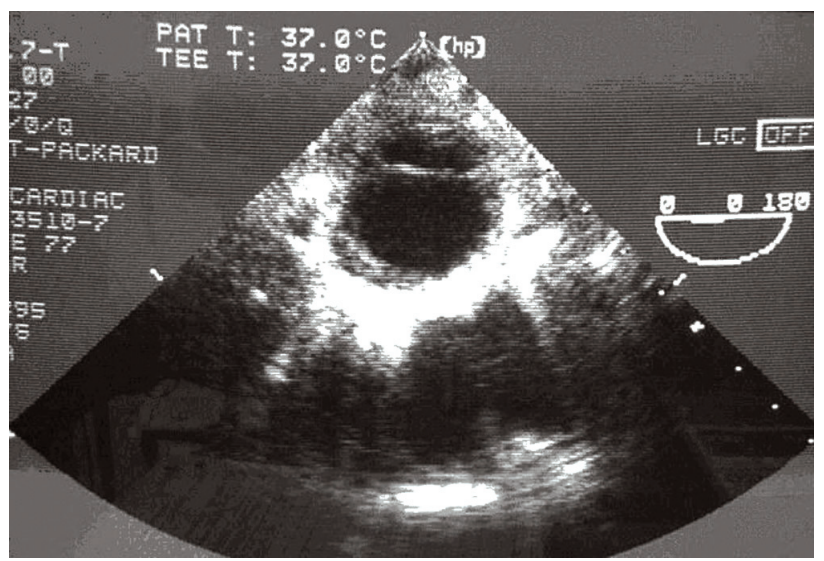

Figure 4 - Transesophageal echocardiography of the aorta indicating an acute aortic injury with double lumen seen. This study was performed intraoperatively during an exploratory laparotomy and showed an intraluminal intimal flap

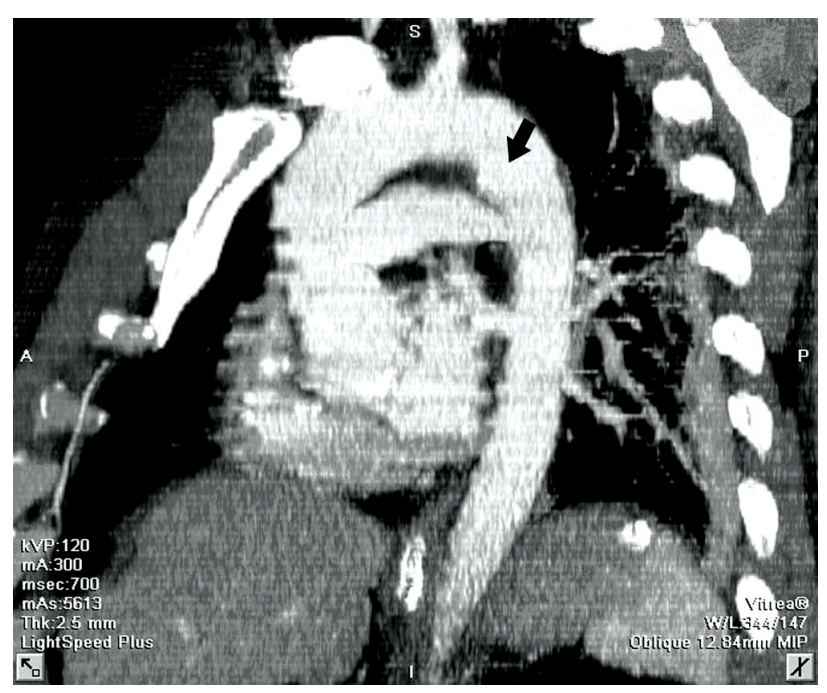

Figure 5 - Sagittal reconstructions of a chest computed tomography angio. The arrow is identifying the traumatic aortic laceration

ning techniques using older model $\mathrm{CT}$ scanners with inadequate volumes of contrast. The latest generation of CT scanners with standardized CTA methods for diagnosis has decreased the number of aortograms without an increase in missed thoracic aortic injury. ${ }^{23}$ Helical chest CT scanning has been used as a screening test in patients with suggestive signs of blunt thoracic aortic injuries on plain chest films. The new helical technology increased the sensitivity of this test and cardiothoracic, as well as trauma surgeons are feeling more comfortable in operating on these patients without aortic angiography. The presence of mediastinal hematoma without clear visualization on a thoracic aortic injury on CT scanning is an absolute indication for angiography. ${ }^{21}$

Transesophageal echocardiography (TEE) initially emerged as an excellent option for diagnosing thoracic aortic rupture (Figure 6). Smith et al. reported sensitivity and specificity of 100 and $98 \%$ respectively in 101 patients that had confirmed injury by aortography. ${ }^{24}$ TEE being rapid, not requiring contrast and its portability offers several advantages to CTA or angiography. However, other studies show TEE to be extremely variable and highly operator-dependent. In 1995, Saletta et al. reviewed TEE as a diagnostic modality in 114 patients with high possibility of aortic trauma reporting an unacceptable sensitivity of $63 \%$ and specificity of $84 \% .{ }^{25}$ Nevertheless, the use of TEE to detect thoracic aortic injury can be helpful during a trauma laparotomy when other imaging modalities have yet to occur. The obtained results should be balanced with the wide variability in TEE sensitivity and specificity and may require definitive evaluation when the patient has physiologically stabilized.

A useful algorithm in detection of thoracic aortic injuries should incorporate the mechanism of injury, patient demographics and initial chest radiograph (Figure 7). In our institution, CTA is the next step in assessing aortic injury if a suspicious chest radiograph is noted or mechanism of injury such as high speed impact or a fall from significant height occurs. Equivocal or positive CTA findings do not necessarily need to be verified by aortography since three-dimensional reconstructions offer significant anatomic clarity; however, the quality of these reconstructions and institutional preference varies considerably.

\section{Treatment}

The initial treatment requires strict adherence to advanced trauma life support (ATLS) principles. The AAST reported an average injury severity score (ISS) of 42 with over $50 \%$ of the patients having significant intracranial trauma, $46 \%$ with multiple rib fractures, 
and $31 \%$ with pelvic fractures (4). Accordingly, the fact that the majority of hypotension in patients with thoracic aortic injury is a result of other associated injuries cannot be overemphasized. ${ }^{26}$ Although uncontrolled hypertension physiologically increases aortic wall tension and propensity for rupture, overcorrection and subsequent iatrogenic hypotension increases the metabolic and physiologic consequences of shock and can increase the rate of secondary brain injury. Thus, unless a patient has stabilized, an adequate survey for concomitant injury has been complete, and the diagnosis of thoracic aortic injury has been established, blood pressure lowering pharmacologic agents should not be used. Often, pain medication works quickly and suffices for initial hypertensive control.

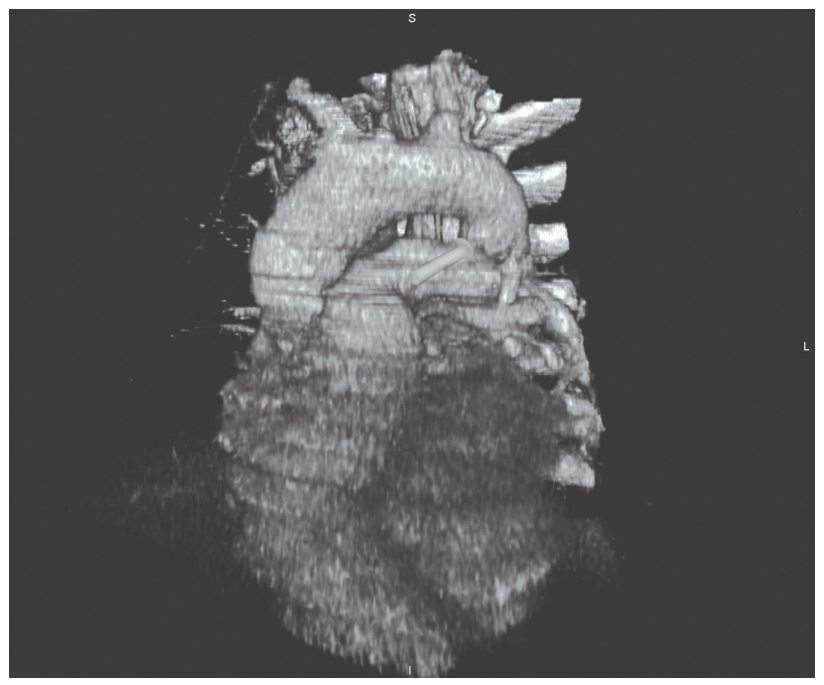

Figure 6 - Three-dimensional reconstruction with tissue subtraction from an angio computed tomography of the chest demonstrating an aortic injury (pseudoaneurysm)

Assessment of other injuries will determine the subsequent management of thoracic aortic injury. Patients who are in physiologic distress or have significant solid organ injury often undergo exploratory laparotomy before the diagnosis of thoracic aortic injury has been assessed. The exact consequence of this on mortality is unknown. However, Hunt et al. in reviewing 144 patients with diagnosed thoracic aortic trauma did not find any measurable difference in mortality in patients undergoing laparotomy before the diagnosis of aortic injury. $^{27}$

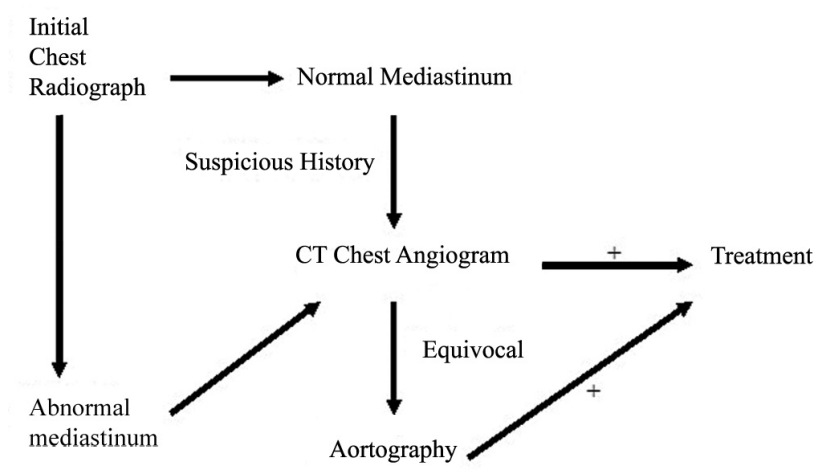

Figure 7 - Algorithm for the diagnosis of traumatic aortic disruption. (Adapted from: Nzewi O, Slight R, Zamvar V. Management of blunt aortic injury. Eur J Vasc Endovasc Surg. 2006;31:18-27)

Once the stability and assessment of a patient have been achieved and the presence of a thoracic aortic injury has been established, the subsequent management can vary considerably. The degree of aortic disruption, the safety of controlling blood pressure, and clinical assessment of the risk of early free rupture versus the patient's overall physiologic prognosis determines whether operative, nonoperative, or endovascular approaches strategies can be used. ${ }^{28}$

The traditional approach to traumatic thoracic aortic injury has been urgent and immediate open repair through a thoracotomy, since in classic teaching delay in repair is associated with greater than $90 \%$ mortality. ${ }^{8}$ However, the paradigm of timing in the classic approach must be challenged for a variety of reasons. Foremost, it is the inherent bias in this patient population since aortic injury has a high incidence of associated injuries, which is the most likely cause of early demise. ${ }^{29}$ Second, the advancement of critical care, injury diagnosis, and the improvement of resuscitation 
and hemodynamic monitoring has markedly improved since the original outcome data were generated.

In an early analysis of 44 patients, Akins et al. reported a 24 to $14 \%$ decrease in the mortality of patients when operative intervention was delayed at least $48 \mathrm{~h} .{ }^{30}$ Several studies since then have demonstrated the safety and reduction in mortality in delayed traumatic aortic repair. ${ }^{31-33}$ There are several important contraindications to consider when selecting patients for operative therapy, all of which are associated with extremely high mortality rates (Table 3). Delaying immediate operative intervention allows time to assess for further injuries, assess prognosis (especially in severe head injury) and maximize resuscitation. However, in implementing a delayed repair strategy, the thoracic aortic injury must be localized and contained without extravasation. Delay does not equate observation; rather, it means pharmacologic intervention and rigorous intensive care unit (ICU) monitoring.

The cornerstone for delayed therapy involves precise control of blood pressure in an effort to reduce aortic wall tension. Initial nonoperative management is predicated on the concept that maintaining a mean arterial pressure of less than or equal to $80 \mathrm{mmHg}$ is possible, since late rupture is uncommon under these circumstances. ${ }^{34}$ Mattox et al. described, in over 500 patients reported in the literature, that patients meeting these strict blood pressure parameters had no deaths secondary to thoracic aortic rupture. ${ }^{35} \beta$-blockers, specifically esmolol, are the preferred antihypertensive agents. These drugs avoid the nitrate-induced reflex tachycardia and the increased myocardial work that occurs with the use of $\alpha$-antagonist. Tight blood pressure monitoring must not mask hypovolemic shock and must take into account the potential of cerebral hypoperfusion in the setting of elevated intracranial pressures.

The rationale for expedient thoracic aortic repair is to prevent delayed rupture and subsequent exsanguination which can occur in up to $12 \%$ of patients with known injury. The mortality of early repair varies from 5 to as high as $54 \%$ with significant morbidity including renal failure, ischemic bowel, cardiac ischemia and a rate of paraplegia reported to be from $5-19 \%{ }^{36}$ The primary complication that is always feared is paraplegia. There are several views on techniques and operative maneuvers to decrease the rate of paraplegia including reduced cross-clamp time, lumbar drains and mechanical circulatory support.

The mandatory use of shunt or bypass in an attempt to decrease the incidence of cord ischemia and its most severe complication, namely paraplegia, is controversial. However, recent reports revealed a decreased incidence of cord ischemia with bypass as compared to cross-clamp. Partial atrial-arterial bypass employing a non-heparinized centrifugal pump is the current preferred technique. The AAST study documented that among those patients who survived operative repair, the incidence of paraplegia was $11.3 \%$ (19\% in clamp-and-

Table 3 - Contraindications to open repair of traumatic aortic injuries

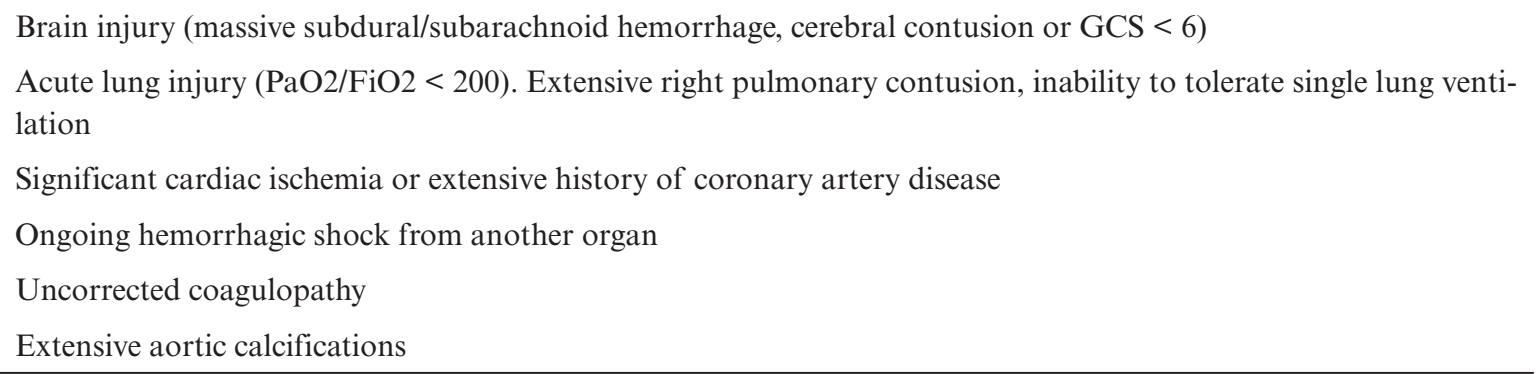


sew and 5.2\% when circulatory support was employed). Many authors believe that mechanical circulatory support may allow some liberalization of the cross-clamp time; however, circulatory support may not be feasible in unstable patients with active bleeding when rapid repair is essential.

\section{Endovascular approach}

The successful use of EVS for aneurysmal disease has given rise to a new option for treating traumatic thoracic aortic injury. This method is especially promising for patients with significant intracerebral hemorrhage, pulmonary contusion, or for elderly patients whose existing comorbidities may preclude an open repair. Many successful case series have been described both in the United States and in Europe with minimal morbidity and mortality. ${ }^{37-39} \mathrm{In}$ a recent publication, 46 blunt thoracic aortic injury patients underwent either EVS or open thoracotomy. Twenty-two patients underwent open repair with a $22.7 \%$ incidence of paraplegia and $13.6 \% 30$-day mortality. The stent group showed $0 \%$ paralysis and $8.3 \%$ mortality rate. ${ }^{40}$ In another study, 18 patients underwent repair of blunt thoracic aortic injuries; six via EVS and 12 through a traditional thoracotomy. There were no significant differences in demographics or injury severity between each group. The open group had a $17 \%$ mortality and a $16 \%$ incidence of paraplegia. This is in contrast to a $0 \%$ rate of mortality and paraplegia in the EVS group. ${ }^{41}$ Peterson et al. treated 11 thoracic aortic rupture patients with commercially available EVS devices with $0 \%$ mortality or paralysis. $^{42}$

Worldwide, 244 cases of acute traumatic aortic injuries repaired through endovascular techniques have been reported to date in MEDLINE. A success rate > $95 \%$ and paraplegia rates of $0 \%$ have been reported. Considering all series, the median follow-up has been of 26 months with one death unrelated to the endovascular approach. The first case series of seven patients treated by the endovascular approach in Brazil was published by Mioto Neto et al., in $2005 .{ }^{43}$ The importance of this initial publication was emphasized by an editorial in the J Vasc Bras by von Ristow. ${ }^{44}$
It is difficult to predict what the future of EVS will be. To date, there is no long-term Level I evidence to verify and recommend EVS as the absolute approach for thoracic aortic injury. However, the short-term complication rate for EVS is substantially lower when compared to open repair. Long term complications of EVS for aortic injury are similar to EVS for aneurysmal disease and include stent migration, endoleak and stent collapse. In one of the longest follow-up studies to date, Hornweg et al. retrospectively analyzed 28 patients in the Netherlands who underwent EVS repair of blunt thoracic aortic injury. ${ }^{45}$ There was no stent-related mortality on a mean follow-up of 26.5 months with only one instance of stent collapse that was corrected.

If the location of injury is within $1 \mathrm{~cm}$ of the left subclavian artery, an inadequate neck for EVS will preclude its usage. ${ }^{46}$ Other considerations including the tortuosity of the aorta, iliac or femoral artery injuries and the length of aortic involvement will not make open repair obsolete. However, available data and experience suggest that EVS may herald new practice guidelines and eventually may replace open repair as the procedure of choice (Figure 8).

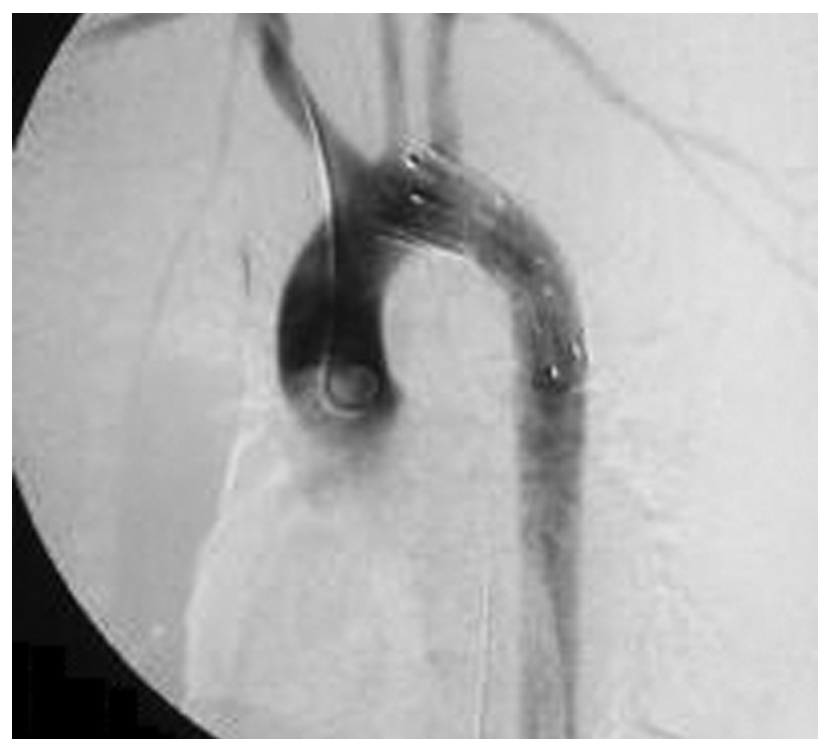

Figure 8 - Thoracic aortic stent graft

\section{Conclusions}

Thoracic aortic rupture remains a highly lethal injury, with most patients dying rapidly in the field. 
Suspicion of these injuries should arise from the patient's history and plain chest radiograph findings. The gold standard for diagnosis is aortic angiography; however, CTA has several advantages with near equivalent sensitivity. If feasible, operative repair should be delayed until the patient has been adequately resuscitated, all concomitant injuries have been identified, and prognosis has been established. Open repair has a very high mortality and morbidity yet has established longterm efficacy. EVS is gaining in popularity and may surpass traditional open repair as standard of care.

\section{References}

1. Tambyraja AL, Scollay JM, Beard D, Henry JM, Murie JA, Chalmers RT. Aortic trauma in Scotland--a population based study. Eur J Vasc Endovasc Surg. 2006;32:686-9. Epub 2006 Jun 5.

2. Chen FH, Shim WH, Chang BC, Park SJ, Won JY, Lee DY. False aneurysms at both ends of a descending thoracic aortic stent-graft: complication after endovascular repair of a penetrating atherosclerotic ulcer. $J$ Endovasc Ther. 2003;10:249-53.

3. Smith RS, Chang FC. Traumatic rupture of the aorta: still a lethal injury. Am J Surg. 1986;152:660-3.

4. Fabian TC, Richardson JD, Croce MA, et al. Prospective study of blunt aortic injury: Multicenter Trial of the American Association for the Surgery of Trauma. J Trauma. 1997;42:374-80.

5. Burkhart HM, Gomez GA, Jacobson LE, Pless JE, Broadie TA. Fatal blunt aortic injuries: a review of 242 autopsy cases. J Trauma. 2001;50:113-5.

6. Balci AE, Kazez A, Eren S, Ayan E, Ozalp K, Eren MN. Blunt thoracic trauma in children: review of 137 cases. Eur J Cardiothorac Surg. 2004;26:387-92.

7. Feczko JD, Lynch L, Pless JE, Clark MA, McClain J, Hawley DA. An autopsy case review of 142 nonpenetrating (blunt) injuries of the aorta. J Trauma. 1992;33:846-9.

8. Parmley LF, Mattingly TW, Manion WC, Jahnke EJ Jr. Nonpenetrating traumatic injury of the aorta. Circulation. 1958;17:1086-101.

9. Cohen AM, Crass JR, Thomas HA, Fisher RG, Jacobs DG. CT evidence for the "osseous pinch" mechanism of traumatic aortic injury. AJR Am J Roentgenol. 1992;159:271-4.

10. Javadpour H, O'Toole JJ, McEniff JN, Luke DA, Young VK. Traumatic aortic transection: evidence for the osseous pinch mechanism. Ann Thorac Surg. 2002;73:951-3.

11. Blackmore CC, Zweibel A, Mann FA. Determining risk of traumatic aortic injury: how to optimize imaging strategy. AJR Am J Roentgenol. 2000;174:343-7.

12. Katyal D, McLellan BA, Brenneman FD, Boulanger BR, Sharkey PW, Waddell JP. Lateral impact motor vehicle collisions: significant cause of blunt traumatic rupture of the thoracic aorta. J Trauma. 1997;42:769-72.
13. Cook J, Salerno C, Krishnadasan B, Nicholls S, Meissner M, Karmy-Jones R. The effect of changing presentation and management on the outcome of blunt rupture of the thoracic aorta. J Thorac Cardiovasc Surg. 2006;131:594-600.

14. Fishman JE. Imaging of blunt aortic and great vessel trauma. J Thorac Imaging. 2000;15:97-103.

15. Mirvis SE, Bidwell JK, Buddemeyer EU, et al. Value of chest radiography in excluding traumatic aortic rupture. Radiology. 1987; 163:487-93.

16. Patel NH, Stephens KE Jr., Mirvis SE, Shanmuganathan K, Mann FA. Imaging of acute thoracic aortic injury due to blunt trauma: a review. Radiology. 1998;209:335-48.

17. Cook AD, Klein JS, Rogers FB, Osler TM, Shackford SR. Chest radiographs of limited utility in the diagnosis of blunt traumatic aortic laceration. J Trauma. 2001;50:843-7.

18. Symbas PJ, Horsley WS, Symbas PN. Rupture of the ascending aorta caused by blunt trauma. Ann Thorac Surg. 1998;66:113-7.

19. Wong H, Gotway MB, Sasson AD, Jeffrey RB. Periaortic hematoma at diaphragmatic crura at helical CT: sign of blunt aortic injury in patients with mediastinal hematoma. Radiology. 2004;231:185-9.

20. Mirvis SE, Shanmuganathan K, Buell J, Rodriguez A. Use of spiral computed tomography for the assessment of blunt trauma patients with potential aortic injury. J Trauma. 1998;45:922-30.

21. Dyer DS, Moore EE, Mestek MF, et al. Can chest CT be used to exclude aortic injury? Radiology. 1999;213:195-202.

22. Miller FB, Richardson JD, Thomas HA, Cryer HM, Willing SJ. Role of CT in diagnosis of major arterial injury after blunt thoracic trauma. Surgery. 1989;106:596-602; discussion 602-3.

23. Bruckner BA, DiBardino DJ, Cumbie TC, et al. Critical evaluation of chest computed tomography scans for blunt descending thoracic aortic injury. Ann Thorac Surg. 2006;81:1339-46.

24. Smith MD, Cassidy JM, Souther S, et al. Transesophageal echocardiography in the diagnosis of traumatic rupture of the aorta. N Engl J Med. 1995;332:356-62.

25. Saletta S, Lederman E, Fein S, Singh A, Kuehler DH, Fortune JB. Transesophageal echocardiography for the initial evaluation of the widened mediastinum in trauma patients. $\mathbf{J}$ Trauma. 1995;39:137-41; discussion 141-2.

26. Hudson HM 2nd, Woodson J, Hirsch E. The management of traumatic aortic tear in the multiply-injured patient. Ann Vasc Surg. 1991;5:445-8.

27. Hunt JP, Baker CC, Lentz CW, et al. Thoracic aorta injuries: management and outcome of 144 patients. J Trauma. 1996;40:547-55.

28. Karmy-Jones R, Jurkovich GJ. Blunt chest trauma. Curr Probl Surg. 2004;41:211-380.

29. Karmy-Jones R, Carter YM, Nathens A, et al. Impact of presenting physiology and associated injuries on outcome following traumatic rupture of the thoracic aorta. Am Surg. 2001;67:61-6.

30. Akins CW, Buckley MJ, Daggett W, McIlduff JB, Austen WG. Acute traumatic disruption of the thoracic aorta: a ten-year experience. Ann Thorac Surg. 1981;31:305-9. 
31. Galli R, Pacini D, Di Bartolomeo R, et al. Surgical indications and timing of repair of traumatic ruptures of the thoracic aorta. Ann Thorac Surg. 1998;65:461-4.

32. Pate JW, Fabian TC, Walker W. Traumatic rupture of the aortic isthmus: an emergency? World J Surg. 1995;19:119-25; discussion 125-6.

33. Maggisano R, Nathens A, Alexandrova NA, et al. Traumatic rupture of the thoracic aorta: should one always operate immediately? Ann Vasc Surg. 1995;9:44-52.

34. Carter YM, Karmy-Jones R, Aldea GS. Delayed surgical management of a traumatic aortic arch injury. Ann Thorac Surg. 2002;73:294-6.

35. Mattox KL, Wall MJ Jr. Historical review of blunt injury to the thoracic aorta. Chest Surg Clin N Am. 2000;10:167-82.

36. von Oppell UO, Dunne TT, De Groot MK, Zilla P. Traumatic aortic rupture: twenty-year metaanalysis of mortality and risk of paraplegia. Ann Thorac Surg. 1994;58:585-93.

37. Rousseau H, Soula P, Perreault P, et al. Delayed treatment of traumatic rupture of the thoracic aorta with endoluminal covered stent. Circulation. 1999;99:498-504.

38. Lachat ML, Pfammatter T, Witzke HJ, et al. Endovascular repair with bifurcated stent-grafts under local anaesthesia to improve outcome of ruptured aortoiliac aneurysms. Eur J Vasc Endovasc Surg. 2002;23:528-36.

39. Brandt M, Hussel K, Walluscheck KP, et al. Stent-graft repair versus open surgery for the descending aorta: a case-control study. J Endovasc Ther. 2004;11:535-8.

40. Andrassy J, Weidenhagen R, Meimarakis G, Lauterjung L, Jauch KW, Kopp R. Stent versus open surgery for acute and chronic traumatic injury of the thoracic aorta: a single-center experience. J Trauma. 2006;60:765-71.
41. Ott MC, Stewart TC, Lawlor DK, Gray DK, Forbes TL. Management of blunt thoracic aortic injuries: endovascular stents versus open repair. J Trauma. 2004;56:565-70.

42. Peterson BG, Matsumura JS, Morasch MD, West MA, Eskandari MK. Percutaneous endovascular repair of blunt thoracic aortic transection. J Trauma. 2005;59:1062-5.

43. Mioto Neto B, Aun R, Estenssoro AEV, Puech-Leão P. Tratamento das lesões de aorta nos traumatismos torácicos fechados. J Vasc Bras. 2005;4:217-26.

44. Von Ristow A. Tratamento das lesões de aorta nos traumatismos torácicos fechados [editorial]. J Vasc Bras. 2005;4:215-6.

45. Hoornweg LL, Dinkelman MK, Goslings JC, et al. Endovascular management of traumatic ruptures of the thoracic aorta: a retrospective multicenter analysis of 28 cases in The Netherlands. J Vasc Surg. 2006;43:1096-102; discussion 1102.

46. Borsa JJ, Hoffer EK, Karmy-Jones R, et al. Angiographic description of blunt traumatic injuries to the thoracic aorta with specific relevance to endograft repair. J Endovasc Ther. 2002;9 Suppl 2:II84-91.

Correspondence:

Raul Coimbra

University of California San Diego

200 W. Arbor Drive, 8896

San Diego, CA

92103-8896

E-mail: rcoimbra@ucsd.edu 